\title{
Professor Gareth Thomas: Colleague, Friend, Mentor, Oenophile, and Rugby Player
}

\author{
Ronald Gronsky ${ }^{1}$, David B. Williams²
}

${ }^{1}$ Department of Materials Science and Engineering, University of California, Berkeley, CA 94720

${ }^{2}$ Department of Materials Science and Engineering, The Ohio State University, Columbus, OH 43210

Both the authors' careers owe much to the electron-microscopy skills, research drive, commitment to teaching, and political networking abilities of Professor Gareth Thomas. A former President of the Electron Microscopy Society of America (1975) and President of the International Federation of Societies for Electron Microscopy (1986-90), Gareth was personally responsible for many special symposia on numerous topics of interest to the membership of MSA. It's now time for a special symposium in his honor. Through these proceedings we remember Gareth as he would like to be remembered, for his many contributions to our favorite discipline and his enduring influence on generations of practicing microscopists, with gratitude to all participants.

One of us (RG) began working with Gareth as a graduate student in 1972, earning both MS and PhD degrees at Berkeley under his mentorship, joining the scientific staff at the Lawrence Berkeley Lab, then accepting a position on the Berkeley faculty, completing his entire professional career within Gareth's orbit. During those formative years, RG benefitted immensely from the effects of Gareth's gravitational field, which attracted many of the world's most highly regarded electron microscopists to Berkeley, enabling opportunities for scholarship that few can imagine. Gareth set a pace and performance standard that continued to challenge all of his protégés throughout his lifetime. The second author (DBW) was also a graduate student when he first met Gareth, who had returned to his PhD institution (Cambridge University) for a sabbatical in the early 1970s. DBW's career path from Lehigh University via the University of Alabama in Huntsville to The Ohio State University was profoundly influenced by the advice and fine wine he received from Gareth over more than 30 years. What may have spurred the latter partnership was a shared love of rugby. Both Gareth and DBW played for Cambridge University, albeit 20 years apart. Their common Welsh names, and an understanding of the essential role of team building (not to mention the accumulated brain damage of many years on the field) colored our experiences and drove our successes.

Gareth's pedagogy extended well beyond the classroom, as RG came to understand early in his graduate "studies." During his Electron Microscopy course, which gave only 3 units of academic credit for 3 hours of lecture and 6 hours of laboratory work every week, Gareth would frequently visit his students' lab sections, instructing them to leave the room while he secretly tripped the dreaded "red bar" on the Siemens Elmiskop IA instruments used in class, calling them back (in a feigned agitated panic) to "fix the problem" and watching how they recovered. Not everyone did, as reflected in their course grades. His message was: "You can't learn everything from textbooks, even mine!" Gareth was equally playful, but much more merciful, during the wine tastings he hosted for his graduate group at least once a semester. These were blind tastings, with mandatory notes on such attributes as "nose" and "legs," to the delight of the many international students in the group, not to mention those of us (RG) who came from Pittsburgh with an "Iron City" reckoning, offering full forgiveness for not recognizing the highly 
ranked vintage that he always provided from his personal cellar among the open bottles. His message was always: "Buy what you like!" Another message that Gareth delivered to RG personally during a quiet session of intense reading at his student desk was: "Don't waste your time reading so many papers; you should be writing them!" This resonated with RG many years later, when he took over as Department Chair and faced having to conduct one of Berkeley's mandatory performance evaluations of his former advisor, Professor Gareth Thomas. After counting up Gareth's publications in the archival literature, his peer-reviewed conference proceedings, and his personally delivered invited talks over the 4 years covered by the performance review, RG calculated an astonishing average of more than 1 scientific contribution per week!

As a graduate student, DBW saw TEM merely as a tool to solve materials problems and consequently was baffled by most of the early TEM textbooks (e.g., HHNPW, Hall, Heidenreich) until he came across Gareth's 1962 text, which was an utter revelation - and mercifully devoid of triple integrals. Upon moving to Lehigh University in 1976, DBW found he was the only faculty member who knew one end of a TEM from the other. He was therefore expected to teach undergraduate and graduate courses in the technique. This was the beginning of what came to be the focus of his subsequent academic career, since he is now far better known for his electron microscopy than for his aluminum-lithium and grainboundary studies. The essential step in DBW's starting his TEM teaching was a letter, carefully typed and mailed, to a dozen or more leading TEM professors around the US, asking for advice on good textbooks from which to teach TEM. Only one professor responded, Gareth Thomas, who not only sent copies of his personal lecture-course notes but also his draft manuscript for the second edition of his 1962 text, now partnering with Mike Goringe (1979). Such outreach from the leading practitioner of TEM in the nation to a very young assistant professor left an indelible impression. DBW has never forgotten Gareth's generosity and was inspired by him to help many other young TEM professors over the intervening 40 years. The practical side of TEM that suffused Gareth's approach to teaching was central to DBW's contribution to his TEM textbook with Barry Carter (who understands all those triple integrals, being a recovering physicist). This book is now the standard teaching text around the world of TEM. It is indeed appropriate that it was Gareth wrote the Foreword to the first edition (Springer 1996).

Both RG and DBW were fortunate to have attended the seminal "Workshop on High Resolution Electron Microscopy" held at the Lawrence Berkeley Laboratory in October of 1976, at which Gareth was truly in his element, shuffling his $35 \mathrm{~mm}$ slides and attacking the podium often to illustrate his points, teaming with collaborators Bob Glaeser at Berkeley and John Cowley from Arizona State University to document the scientific case for massive funding in support of electron microscopy, and painstakingly cultivating interest in establishing what is now the National Center for Electron Microscopy (NCEM) to be located in, of all places, Berkeley! This event was a networking opportunity par excellence since all the nation's microscopists were present. DBW was able to start his career in the US by getting to know a full spectrum of other microscopists from the well established, through to Gareth's newly-minted PhDs at the time, which of course included the primary author of this paper and co-organizer of this symposium, RG, who worked with Gareth to make NCEM a reality. Of course NCEM continues to this day as one of Gareth's many enduring legacies, more of which will be revealed throughout the course of this special symposium. 